In group 1, 17 of 23 patients (74\%) had no complications. The wound broke down in four patients after removal of sutures. Although these patients had no clinical evidence of infection, wound cultures grew aerobic and anaerobic organisms in three of the four cases. Two other patients required early removal of sutures on the second and ninth postoperative days for wound haematoma and wound infection respectively. There was no evidence of recurrence in either group at six and 12 months follow up.

\section{Comment}

Successful day case excision and primary closure of natal cleft sinus is feasible and offers earlier healing than excision and healing by secondary intention. Although primary closure was not always successful, the time to complete healing of unsuccessful cases was not significantly different from that of the secondary healing group (median difference $-4 ; 95 \%$ confidence interval -10 to 3 ).

The failure rate in group 1 is higher than that reported elsewhere.' Four of the six patients who failed to heal had bacteriological evidence of wound infection. Kronborg $e t a l$ have reported that the prophylactic use of clindamycin reduced healing time after primary closure. ${ }^{3}$ None of our patients received prophylactic antibiotics, and no subcutaneous sutures were used. Use of the outpatient department and district nurse was lower in group 1 than group 2. (Further clinical details can be obtained from the author.)

This study shows that excision and primary closure of uncomplicated natal cleft sinus is less costly and more effective than secondary healing. Although the procedure was unsuccessful for some patients, secondary healing occurred without any increase in the overall time to healing compared with secondary healing only. Widespread use of primary closure could reduce health care expenditure and patients' time off work. Further studies are required to compare excision and primary closure to other potentially cost effective methods of treatment.

We are grateful to surgeons in Portsmouth District Health Authority for allowing us to study their patients.

Allen-Mersh TG. Pilonidal sinus: finding the right track for treatment. BrF Surg 1990;77:123-32.

2 Gardner MJ, Altman DG. Statistics with confidence. London: British Medical Journal, 1990 .

3 Kronborg O, Christensen KI, Zimmermann-Nielsen O. Chronic pilonidal disease: a randomised trial with complete 3-year follow up. Br $\mathcal{F}$ Surg disease: a rand

(Accepted 11 November 1991)

\title{
Use of Lucozade and glucagon by ambulance staff for treating hypoglycaemia
}

\section{J M Steel, J Allwinkle, R Moffat, D J Carrington}

Department of Diabetes, Royal Infirmary of Edinburgh, Edinburgh EH3 9YW

J M Steel, associate specialist J Allwinkle, diabetic liaison nurse

Scottish Ambulance Service, Fife, Lothian and Borders Area, Edinburgh EH10 5SA

R Moffat, area training officer D J Carrington, chief ambulance officer

$B M 7$ 1992;304:1283-4
Severe hypoglycaemia is a serious and much feared complication of insulin treatment. Intensive treatment with insulin makes it more likely to occur. ${ }^{1}$ Hypoglycaemia may cause physical damage and transient or permanent neurological damage, and occasionally it causes cerebral oedema and death.

In an attempt to reduce morbidity and hospital admissions we trained all ambulance staff (not only "paramedics") how to measure blood glucose concentrations and treat hypoglycaemia with oral glucose and subcutaneous glucagon.

\section{Methods and results}

All ambulance staff in the Lothian region were instructed by a series of tutorials and demonstrations how to recognise and treat hypoglycaemia. They were taught how to measure blood glucose concentrations with test strips and instructed to do this for any patient they thought could be hypoglycaemic. If the concentration was less than $4 \mathrm{mmol} / \mathrm{l}$ they were instructed to give a tumbler of Lucozade (oral glucose); if this was impossible they were to give $1 \mathrm{mg}$ of glucagon subcutaneously, followed on recovery by Lucozade. Patients were taken to an accident and emergency
Condition of 103 diabetic patients with severe hypoglycaemia on arrival of ambulance staff and outcome after treatment with oral or subcutaneous glucose

\begin{tabular}{|c|c|c|c|c|c|c|}
\hline & & \multirow[b]{2}{*}{ Confused } & \multirow[b]{2}{*}{ Agitated } & \multicolumn{3}{|c|}{ Unconscious } \\
\hline & & & & Fitting & $\begin{array}{l}\text { Responding } \\
\text { to pain }\end{array}$ & $\begin{array}{l}\text { Not } \\
\text { responding } \\
\text { to pain }\end{array}$ \\
\hline Total No & 103 & 68 & 62 & 20 & 31 & 8 \\
\hline No not taken to hospital & 24 & 13 & 18 & 4 & 5 & 1 \\
\hline $\begin{array}{l}\text { No given no treatment or oral } \\
\text { treatment }\end{array}$ & 62 & 46 & 34 & 13 & 20 & 4 \\
\hline No given intravenous treatment & 10 & 6 & 5 & 1 & 3 & 2 \\
\hline
\end{tabular}

department unless they signed a form refusing to go. Clinical details were recorded on 153 calls in which the patients were suspected of being hypoglycaemic.

There were 103 hypoglycaemic episodes in 88 insulin treated diabetic patients ( 32 women, 56 men) over the nine month period of the study. Twenty six episodes were treated with Lucozade only and 76 with glucagon. One patient was so uncooperative that treatment was impossible. Twenty four patients recovered quickly and refused to go to hospital. Sixty two were discharged from the accident and emergency department after either no treatment, oral glucose, or "tea and toast." Ten were given intravenous glucose and discharged without admission. Seven were admitted but in no case was this for further treatment of hypoglycaemia. The responses of the patients were not related to their clinical state (table). In eight episodes (seven men) alcohol was mentioned as a relevant factor.

Two episodes of hypoglycaemia occurred in diabetic patients receiving a sulphonylurea drug. One was treated with Lucozade and the other with glucagon; neither required hospital treatment.

Seventeen diabetic patients were not hypoglycaemic. Five were hyperglycaemic and the others had problems unrelated to diabetes.

Thirty one patients were later found not to be diabetic. Six of these, however, were hypoglycaemic. Two were wives of diabetics who had taken an intentional overdose of insulin: one recovered after Lucozade; the other was the only patient in the series requiring inpatient treatment for hypoglycaemia. The four other hypoglycaemic patients were intoxicated with alcohol.

\section{Comment}

Ambulance staff in Cardiff have reported the use of intravenous dextrose in the management of hypoglycaemia. ${ }^{2}$ This can be difficult in a restless or convulsing patient and there is a risk of venous sclerosis of precious veins and of tissue necrosis. These disadvantages greatly outweigh the advantage of a very slightly faster recovery. ${ }^{34} \mathrm{~A}$ report from Norwich records the experience of paramedics giving glucagon to 28 patients, ${ }^{5}$ but more can be treated if all ambulance staff are involved. 
As this is not a controlled study it is not possible to prove that the number of hospital admissions from hypoglycaemia was reduced, but it is likely that some of 103 hypoglycaemic episodes in insulin dependent diabetic patients would have resulted in admission to hospital for treatment of hypoglycaemia if the patients had not received treatment by ambulance staff. Ten patients required intravenous glucose over nine months; this contrasts with 50 patients who required intravenous glucose in the same hospital over a seven month period in 1987 (A Collier, personal communication. $)^{3}$

The ambulance staff were very enthusiastic and the patients grateful. We believe that the administration of Lucozade and glucagon by ambulance personnel is safe, effective, and financially beneficial. We recommend its extension to other areas.
This practice has recently been extended to all of Scotland. We thank Dr K Little, Dr C Robertson, Beechams, Boehringer Mannheim, and Novo-Nordisk.

1 Diabetes Control and Complications Trial Research Group. Epidemiology of severe hypoglycaemia in the diabetes control and complications trial. Am f Med 1991;90:450-9.

2 Weston C, Stephens $M$. Hypoglycaemic attacks treated by ambulance personne with extended training. BMF 1990;300:908-9.

3 Collier A, Steedman DJ, Patrick AW, Matthews DM, Clarke BF, Little K. Comparison of intravenous glucagon and dextrose in treatment of severe Comparison of intravenous glucagon and dextrose in treatment of severe 1987:10:712-5.

4 Mulhauser I, Koch J, Berger M. Pharmacokinetics and bioavailability of injected glucagon: differences between intramuscular, subcutaneous and intravenous administration. Diabetes Care 1985;8 (suppl 1):39-42.

5 Yaxley L, Aldridge V, Almond J, Harradence F, Henry P, Heyburn PJ, et al. The treatment of severe hypoglycaemia with glucagon administered by ambulance personnel. Diabetic Med 1991;8 (suppl 1):71.

(Accepted 19 February 1992)
Queen Elizabeth Hospital, Edgbaston, Birmingham B15 2TH

I Greaves, registrar in nephrology and general medicine

A J Grant, house physician

D A Heath, honorary consultant physician

J Michael, consultant physician and nephrologist D Adu, consultant physician and nephrologist

Correspondence to: Dr Heath, department of medicine.

BMF 1992;304:1284

\section{Hypercalcaemia: changing causes over the past 10 years}

\author{
I Greaves, A J Grant, D A Heath, J Michael, \\ D Adu
}

In previous surveys in this hospital we have found malignancy to be the commonest cause of hypercalcaemia. In a retrospective survey hyperparathyroidism accounted for $13 \%$ of cases, $22 \%$ of cases being of unknown cause. ${ }^{1}$ In a subsequent, prospective study ${ }^{2}$ it was suggested that most of the cases of unexplained hypercalcaemia were due to primary hyperparathyroidism. In both surveys hypercalcaemia associated with renal failure was uncommon. We have recently completed a three month review of all hypercalcaemic patients in the same hospital and report here the results.

\section{Patients, methods, and results}

In the three months from May to July 1990, 181 hypercalcaemic patients with a corrected calcium concentration of greater than $2.7 \mathrm{mmol} / \mathrm{l}$ were identified from our biochemistry department computer database (correction factor: $0.02 \mathrm{mmol}$ calcium per 1 was added or subtracted/g albumin above or below $40 \mathrm{~g} / \mathrm{l}$ ). The notes of 162 of these patients were subsequently obtained; the remainder could not be identified. Half the cases of hypercalcaemia were in patients in chronic renal failure. Patients were dialysed against a calcium concentration of $1.75 \mathrm{mmol} / \mathrm{l}$. The comparison of the causes of hypercalcaemia in the three series is shown in the table.

In 1980 and 1981 we commented on the infrequent effective treatment of the hypercalcaemia of malignancy. In this new survey only five out of 30 patients received bisphosphonate, which is perhaps the current treatment of choice. ${ }^{3}$ Although retrospective assessment of

Causes of hypercalcaemia in the three series. Figures are numbers of patients

\begin{tabular}{lccc}
\hline & $\begin{array}{c}1990 \\
\text { Survey }\end{array}$ & $\begin{array}{c}\text { Retrospective } \\
\text { survey }\end{array}$ & $\begin{array}{c}\text { Prospective }^{1} \\
\text { survey }^{2}\end{array}$ \\
\hline $\begin{array}{l}\text { Chronic renal failure } \\
\text { After renal transplantation }\end{array}$ & $\begin{array}{c}81(50 \%) \\
\text { Malignancy }\end{array}$ & $68(15 \%)$ & $6(3.9 \%)$ \\
After liver transplantation & 35 & 219 & 89 \\
$\begin{array}{l}\text { Primary hyperparathyroidism } \\
\text { Unexplained }\end{array}$ & 9 & 59 & 53 \\
Other & 10 & 102 & 6 \\
\hline Total & 1 & 18 & 6 \\
\hline
\end{tabular}

the need for treatment in malignant hypercalcaemia is difficult, we suspect that adequate treatment of this condition remains inconsistent. All the cases of primary hyperparathyroidism in our survey were routine admissions for surgery. In view of our previous experience it is likely that the unexplained hypercalcaemia was due to primary hyperparathyroidism.

\section{Comment}

The most surprising change over the past decade has been the enormous increase in hypercalcaemia associated with chronic renal failure, which occurred in 81 of the 162 patients in our survey. In 32 patients the calcium concentration was greater than $3.0 \mathrm{mmol} / \mathrm{l}$. Fifty three of the 81 patients were receiving calcium or vitamin D supplementation, and in 44 cases the serum calcium concentration returned to normal after reducing or stopping vitamin $\mathrm{D}$ or calcium supplementation. Twenty patients had hypercalcaemia which settled without treatment. Only two of the 81 patients subsequently required parathyroidectomy. Twenty one patients in our study developed hypercalcaemia after receiving a renal transplant. Two of these patients became normocalcaemic after stopping calcium supplementation. The others did not require treatment.

In this study there were five cases of transient perioperative hypercalcaemia in liver transplant recipients, probably due to the large intraoperative infusion of calcium during the transplant operation.

The incidence of hypercalcaemia among renal patients seems, at least in part, to be due to calcium carbonate replacing aluminium hydroxide as a phosphate binder, with its concomitant advantages of the avoidance of aluminium toxicity and simultaneous calcium supplementation. The increased incidence of hypercalcaemia with calcium carbonate has been noted in previous studies. ${ }^{4}$ Although the incidence of symptomatic hypercalcaemia seemed low, we suggest that the treatment of the hypercalcaemia of chronic renal failure with calcium supplements should be monitored more carefully.

We were disappointed that the treatment of the hypercalcaemia of malignancy seemed not to have improved over 10 years despite marked improvement in the efficacy of therapeutic measures available.

1 Fisken RA, Heath DA, Bold AM. Hypercalcaemia-a hospital survey. $Q \mathcal{f} M e$ 1980;196:405-18

2 Fisken RA, Heath DA, Somers S, Bold AM. Hypercalcaemia in hospita patients. Lancet 1981 ; i:202-6.

3 Heath DA. The treatment of hypercalcaemia of malignancy. Clin Endocrino 1991;34:155-7.

4 Malluche H, Faugere MC. Renal bone disease 1990: an unmet challenge for the nephrologist. Kidney Int 1990;39:193-211.

(Accepted 13 February 1992) 